\title{
Prediction of Impact Resistance Properties of Concrete Using Radial Basis Function Networks
}

\author{
S. Yazici, G. InAn SEzer* And A. Sezer \\ Ege University, Faculty of Engineering, Department of Civil Engineering, Izmir, Turkey
}

\begin{abstract}
This study presents an investigation of the prediction of impact resistance of steel-fiber-reinforced concrete and ordinary concrete specimens. In the experimental part of this study, parameters identifying impact resistance of various concrete mixtures were determined using an impact test machine, in accordance with ACI Committee 544 . For this aim, concrete specimens containing three different aggregates (basalt, limestone and natural aggregate) were cured in water at $20^{\circ} \mathrm{C}$ for 28 days. After curing impact resistance tests were performed on specimens having compressive strength values between 20 and $50 \mathrm{MPa}$, to determine the blows to initial crack and failure. The specimens were also subjected to splitting tensile strength and ultrasonic pulse velocity tests. Initially, using blows to initial crack and failure, many attempts were made to classify the impact resistance of different types of concrete in terms of the origin of used aggregate, strength properties or ultrasonic pulse velocity, however, this made no sense. The specimens could only be classified in terms of steel fiber presence. Therefore, radial basis function network, which belongs to another kind of unsupervised classifier network, was used to estimate the two abovementioned impact resistance parameters. In this scope, independent from aggregate origin used in preparation of specimens, compressive strength, splitting tensile strength and ultrasonic pulse velocity of the specimens were used to predict the impact resistance parameters of the concrete specimens. The results revealed that three listed parameters can be used for estimation of blows to formation of initial crack and failure. Scatter plots, root mean square error and absolute value of average residual parameters were used to verify the errors in predictions, which were very low, compared with the uncertainty in test and ambiguity of data in hand.
\end{abstract}

DOI: 10.12693/APhysPolA.132.1036

PACS/topics: 81.70.Bt, 79.20.Ap, 07.05.Mh

\section{Introduction}

Concrete structures can be subjected to impact loads, such as air blasts, falling weights and earthquakes loading, etc. $[1,2]$, along with static loads. Since tensile strength of concrete is lower then its compressive strength, the control of crack propagation is more difficult. Fibers can be used to improve impact properties of concrete $[1,3]$. Fiber is a good alternative, which can be used to improve impact resistance properties and control crack propagation in concrete [3].

On the other hand, determination of impact resistance of concrete is a laborious task and estimation of parameters identifying this property, using strength properties may be a practical approach. In the literature, a number of studies concerning estimation of impact properties are available. Zhan et al. [1] investigated the relationship between several characteristics, including drop height, static flexural load-carrying capacity and input impact energy. They proposed two empirical formulas to estimate the maximum and residual deflection of a beam, based on the static flexural load-carrying capacity and the input impact energy.

Aghdamy et al. [4] presented a numerical study of the response of axially loaded concrete-filled steel tube columns (CFST) under lateral impact loading, using

*corresponding author; e-mail: gozde.sezer@ege.edu.tr explicit non-linear finite element techniques. They revealed that findings can be employed in future to simplify assumptions on the CFST column behavior under impact loading and to develop appropriate design calculation methods for CFST columns under such loading conditions.

Jiang and Chorzepa [5] present an effective analysis procedure, to perform a failure analysis of pre-stressed concrete members, subjected to lateral impact loads, using the finite element analysis program, LS-DYNA. Their study shows that the proposed method can be used to predict the response of axially loaded columns for accidentally applied lateral impact loads, resulting from a car or vessel crash.

In this study, several attempts were made to estimate impact properties of concrete mixtures, including blows to formation of initial crack and failure. The inputs for estimation of above mentioned properties were selected as compressive strength, splitting tensile strength and ultrasonic pulse velocity, since application of tests to obtain these parameters are more common and relatively easier, in comparison with impact resistance tests.

\section{Experimental study}

In preparation of specimens, CEM I 42.5 type Portland cement was used. $\mathrm{C}_{3} \mathrm{~S}, \mathrm{C}_{2} \mathrm{~S}, \mathrm{C}_{3} \mathrm{~A}$ and $\mathrm{C}_{4} \mathrm{AF}$ contents of cement are $61.00,8.82,7.57$ and $10.68 \%$, respectively. Crushed limestone aggregate with the size of $0-5 \mathrm{~mm}$ was used as a fine aggregate. Three aggregates having different origins (limestone, basalt and natural aggregate) 
were used as coarse aggregate, with maximum sizes of 10, 15, 20 and $25 \mathrm{~mm}$. Aggregates were recombined to a specified uniform grading during mixing [6]. The blend consisted of $55 \%$ of fine aggregate and $45 \%$ of coarse aggregate.

Hooked-end bundled steel fibers with $l / d$ ratio of 65 and $1.0 \%$ volumetric ratio were used in production of fiber reinforced concrete mixtures. Water/cement ratio and cement dosage of concrete mixtures are 0.5 and $400 \mathrm{~kg} / \mathrm{m}^{3}$, respectively. Slump values of concrete mixtures were kept constant at $100 \pm 20 \mathrm{~mm}$. 24 concrete mixtures (12 ordinary and 12 steel fiber reinforced concrete mixtures) were produced.

After 28 days of standard curing, compressive strength, splitting tensile strength and ultrasonic pulse velocity tests were performed on $150 \times 150 \times 150 \mathrm{~mm}^{3}$ cube specimens. Additionally, impact resistances of concrete specimens were determined using impact test apparatus, described in ACI 544.3R-93. Cylinders with the size of $150 \times 300 \mathrm{~mm}$ were prepared for impact resistance tests. After 28 days of curing, these specimens were cut and discs with sizes of $150 \times 64 \mathrm{~mm}$ (diameter $\times$ thickness) were prepared. Impact resistance tests were performed on these discs. Number of blows to formation of initial crack and failure were determined. The obtained results are summarized in Tables I-III.

TABLE I

Results of tests performed on samples containing limestone aggregates.

\begin{tabular}{c|c|c|c|c|c|c}
\hline \hline $\begin{array}{c}\text { MAS } \\
{[\mathrm{mm}]}\end{array}$ & $\begin{array}{c}\text { FV } \\
{[\%]}\end{array}$ & $\begin{array}{c}\text { CS } \\
{[\mathrm{MPa}]}\end{array}$ & $\begin{array}{c}\text { STS } \\
{[\mathrm{MPa}]}\end{array}$ & $\begin{array}{c}\text { UPV } \\
{[\mathrm{m} / \mathrm{s}]}\end{array}$ & BIC & BF \\
\hline 25 & 0 & 32.2 & 3.42 & 4402 & 25 & 33 \\
25 & 0 & 33.9 & 3.75 & 4456 & 36 & 39 \\
25 & 0 & 35.1 & 3.53 & 4445 & 28 & 30 \\
25 & 1 & 36.3 & 3.89 & 4368 & 232 & 292 \\
25 & 1 & 35.1 & 4.06 & 4396 & 245 & 312 \\
25 & 1 & 35.7 & 3.77 & 4388 & 228 & 315 \\
20 & 0 & 34.8 & 3.69 & 4438 & 28 & 33 \\
20 & 0 & 34.2 & 3.55 & 4463 & 34 & 37 \\
20 & 0 & 35.5 & 3.79 & 4466 & 39 & 42 \\
20 & 1 & 37.1 & 4.10 & 4386 & 241 & 305 \\
20 & 1 & 37.3 & 4.01 & 4391 & 230 & 300 \\
20 & 1 & 36.0 & 4.31 & 4379 & 257 & 341 \\
15 & 0 & 33.7 & 3.83 & 4456 & 34 & 35 \\
15 & 0 & 35.9 & 3.68 & 4489 & 38 & 43 \\
15 & 0 & 36.6 & 4.08 & 4496 & 32 & 35 \\
15 & 1 & 36.9 & 4.36 & 4436 & 242 & 302 \\
15 & 1 & 38.1 & 4.07 & 4404 & 229 & 326 \\
15 & 1 & 36.7 & 4.26 & 4448 & 259 & 322 \\
10 & 0 & 37.1 & 4.06 & 4466 & 39 & 43 \\
10 & 0 & 35.3 & 3.96 & 4471 & 32 & 35 \\
10 & 0 & 36.5 & 3.68 & 4493 & 41 & 44 \\
10 & 1 & 37.2 & 4.16 & 4409 & 236 & 312 \\
10 & 1 & 38.2 & 4.21 & 4431 & 251 & 308 \\
10 & 1 & 37.6 & 4.46 & 4443 & 256 & 342
\end{tabular}

In Tables I to III, AT, MAS, FV, CS, STS, UPV, BIC and $\mathrm{BF}$ stand for maximum aggregate size, fiber volume, compressive strength, splitting tensile strength, ultrasonic pulse velocity, blows to formation of initial crack and blows to failure, respectively.

TABLE II

Results of tests performed on samples containing basalt aggregates.

\begin{tabular}{c|c|c|c|c|c|c}
\hline \hline $\begin{array}{c}\text { MAS } \\
{[\mathrm{mm}]}\end{array}$ & $\begin{array}{c}\text { FV } \\
{[\%]}\end{array}$ & $\begin{array}{c}\text { CS } \\
{[\mathrm{MPa}]}\end{array}$ & $\begin{array}{c}\text { STS } \\
{[\mathrm{MPa}]}\end{array}$ & $\begin{array}{c}\text { UPV } \\
{[\mathrm{m} / \mathrm{s}]}\end{array}$ & BIC & BF \\
\hline 25 & 0 & 35.2 & 3.48 & 4472 & 29 & 34 \\
25 & 0 & 36.4 & 3.57 & 4496 & 35 & 36 \\
25 & 0 & 35.7 & 3.71 & 4428 & 34 & 36 \\
25 & 1 & 37.9 & 3.78 & 4408 & 228 & 292 \\
25 & 1 & 36.5 & 4.26 & 4395 & 256 & 307 \\
25 & 1 & 38.1 & 3.85 & 4386 & 240 & 317 \\
20 & 0 & 36.1 & 3.56 & 4445 & 34 & 36 \\
20 & 0 & 37.9 & 3.77 & 4466 & 33 & 33 \\
20 & 0 & 36.8 & 3.67 & 4432 & 39 & 42 \\
20 & 1 & 38.5 & 4.33 & 4402 & 236 & 302 \\
20 & 1 & 40.2 & 4.11 & 4395 & 245 & 321 \\
20 & 1 & 37.8 & 3.95 & 4432 & 264 & 322 \\
15 & 0 & 37.6 & 3.72 & 4456 & 35 & 39 \\
15 & 0 & 36.0 & 3.66 & 4489 & 42 & 45 \\
15 & 0 & 38.1 & 4.09 & 4507 & 33 & 35 \\
15 & 1 & 39.5 & 4.06 & 4389 & 232 & 312 \\
15 & 1 & 40.5 & 4.29 & 4404 & 255 & 302 \\
15 & 1 & 38.3 & 4.2 & 4448 & 264 & 332 \\
10 & 0 & 38.2 & 4.06 & 4507 & 39 & 43 \\
10 & 0 & 36.8 & 3.96 & 4496 & 32 & 36 \\
10 & 0 & 37.8 & 3.68 & 4488 & 45 & 46 \\
10 & 1 & 38.2 & 4.09 & 4443 & 236 & 343 \\
10 & 1 & 41.2 & 4.33 & 4431 & 262 & 308 \\
10 & 1 & 39.4 & 4.29 & 4456 & 256 & 313 \\
& & & & & &
\end{tabular}

\section{Computational tools for modeling the impact resistance}

Experiments for determination of several properties of concrete may be a hard and laborious task, and prediction could be a better way to analyze their behavior. Computational tools, particularly, soft computing and linear/nonlinear regression methods are beneficial for modeling several properties of concrete, as was demonstrated in past studies [7, 8]. Initially, it was considered to classify the impact resistance of steel fiber reinforced/ordinary concrete using unsupervised clustering algorithms.

\subsection{Unsupervised clustering algorithms for classification of impact resistance}

Clustering is simply defined as grouping of data components in terms of similarity of the different aspects. Algorithmic approaches including hard $k$-means (HKM), 
TABLE III

Results of tests performed on samples containing natural aggregates.

\begin{tabular}{c|c|c|c|c|c|c}
\hline \hline $\begin{array}{c}\text { MAS } \\
{[\mathrm{mm}]}\end{array}$ & $\begin{array}{c}\text { FV } \\
{[\%]}\end{array}$ & $\begin{array}{c}\text { CS } \\
{[\mathrm{MPa}]}\end{array}$ & $\begin{array}{c}\text { STS } \\
{[\mathrm{MPa}]}\end{array}$ & $\begin{array}{c}\text { UPV } \\
{[\mathrm{m} / \mathrm{s}]}\end{array}$ & BIC & BF \\
\hline 25 & 0 & 33.5 & 3.21 & 4472 & 29 & 33 \\
25 & 0 & 30.2 & 3.39 & 4435 & 29 & 38 \\
25 & 0 & 31.7 & 3.21 & 4428 & 37 & 28 \\
25 & 1 & 36.4 & 3.54 & 4356 & 218 & 298 \\
25 & 1 & 34.6 & 3.7 & 4395 & 235 & 307 \\
25 & 1 & 34.6 & 3.59 & 4386 & 242 & 277 \\
20 & 0 & 34.1 & 3.58 & 4445 & 30 & 30 \\
20 & 0 & 32.2 & 3.27 & 4466 & 37 & 37 \\
20 & 0 & 30.7 & 3.33 & 4432 & 33 & 34 \\
20 & 1 & 35.9 & 3.56 & 4402 & 234 & 305 \\
20 & 1 & 34.2 & 3.72 & 4395 & 221 & 279 \\
20 & 1 & 37.0 & 3.67 & 4382 & 241 & 305 \\
15 & 0 & 32.3 & 3.68 & 4477 & 35 & 34 \\
15 & 0 & 34.5 & 3.38 & 4489 & 37 & 39 \\
15 & 0 & 33.8 & 3.48 & 4496 & 29 & 32 \\
15 & 1 & 36.7 & 3.76 & 4366 & 230 & 293 \\
15 & 1 & 35.7 & 3.6 & 4404 & 242 & 281 \\
15 & 1 & 38.0 & 3.83 & 4389 & 231 & 320 \\
10 & 0 & 34.3 & 3.55 & 4504 & 35 & 34 \\
10 & 0 & 33.7 & 3.63 & 4523 & 35 & 35 \\
10 & 0 & 35.7 & 3.79 & 4465 & 41 & 44 \\
10 & 1 & 36.3 & 3.78 & 4409 & 256 & 308 \\
10 & 1 & 38.2 & 3.89 & 4356 & 222 & 295 \\
10 & 1 & 37.2 & 3.87 & 4443 & 243 & 312
\end{tabular}

TABLE IV

Ranges for several properties of steel fiber reinforced and non-reinforced concrete mixtures.

\begin{tabular}{c|c|c}
\hline \hline Parameter & $\begin{array}{c}\text { Steel fiber } \\
\text { reinforced concrete }\end{array}$ & $\begin{array}{c}\text { Ordinary } \\
\text { concrete }\end{array}$ \\
\hline CS [MPa] & $34.2-41.2$ & $30.2-38.2$ \\
STS [MPa] & $3.54-4.46$ & $3.21-4.09$ \\
UPV [m/s] & $4356-4466$ & $4402-4523$ \\
BIC & $218-264$ & $25-45$ \\
BF & $277-343$ & $28-46$
\end{tabular}

fuzzy $c$-means (FCM) and self-organizing maps (SOM) can be used to group the data objects of similar properties. In these approaches, the intra-cluster distances are minimized and inter-cluster distances are maximized using iterative calculation procedures. In HKM algorithm, a set of $n$ objects is classified into $c$ clusters, and the number of clusters should be selected at the beginning of the iterative procedure. Each data object can belong to only one cluster. The objective function, denoting the sum of inter-cluster distances is minimized to find out a local minimum, and this minimum is generally quickly converged. It should be mentioned that, the selection of cluster center points may significantly influence the outcomes. On the other hand, FCM algorithm could be identified as an advanced $k$-means algorithm [9]. Contrary to HKM algorithm, FCM algorithm assigns a single data point as a member to more than one cluster, each data point has a degree of membership (or probability) of belonging to each cluster. The biggest membership value is used to determine to which cluster a data point "most probably" belongs to.

Introduced by Kohonen [10], SOM is a kind of neural network, and spatial locations of the neurons, based on statistical features of inputs, are used to constitute a topographic map of the inputs. As an unsupervised neural network, it is based on a "winner takes all" rule [11]. Using the topological neighborhood principle, output neurons compete with each other to be the winning neuron [12]. Details of the three algorithms can be found elsewhere $[13,14]$.

Three methods, namely, HKM, FCM and SOM are employed to classify the characteristics of the data in hand. Nevertheless, the data including results of compressive strength, splitting tensile strength, ultrasonic pulse velocity, the number of blows leading to failure and formation of initial crack could not be clustered. These parameters belong to concretes of different types, and are completely different from each other. However, these methods were incapable of classifying strength or impact resistance of different types of concrete. The observed range of the experimentally obtained parameters for ordinary and steel fiber reinforced concretes are given in Table IV. Although these parameters can be used for classification of steel fiber reinforced and ordinary concrete, this made no sense. The target was to classify the different types of concrete or concrete produced using aggregates of different origin.

The classification results are given in Fig. 1.

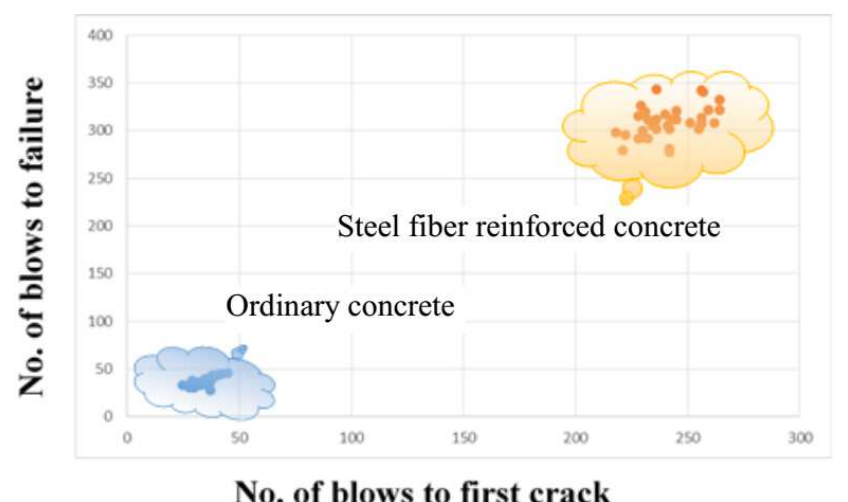

Fig. 1. Classification of reinforced and ordinary concrete using impact resistance data.

\subsection{Prediction of impact resistance of concrete using radial basis functions}

Introduced by Broomhead and Lowe [15], radial basis function (RBF) is actually a sophisticated linear regression model. To solve a classification problem, this network measures similarity of input data to training set. 
RBF neurons store indicative values from the training dataset. RBFs therefore initially cluster the data and various locally tuned non-linear activation functions cover a region of the input lattice. A sample RBF is illustrated in Fig. 2, which includes input and hidden layers, including same number of neurons, and an output layer [16]. Herein, in order to get rid of the dimension problems, transformation of the inputs is strictly needed. A radial basis function is utilized for this aim. Output layer serves as a linear regressor, and weights should be adjusted. A generalized RBF network can be formulated as:

$$
y(x)=\varphi\left[\frac{(x-c)^{T}(x-c)}{r^{2}}\right] .
$$

In this equation, $\varphi$ is the activation function, $r$ is the scalar radius, $c$ is the center. The Euclidean distance $r_{j}$ can be calculated using Eq. (2) [17]:

$$
r_{j}=\sqrt{\sum_{i=1}^{m}\left(y_{i}-w_{i j}\right)^{2}} .
$$

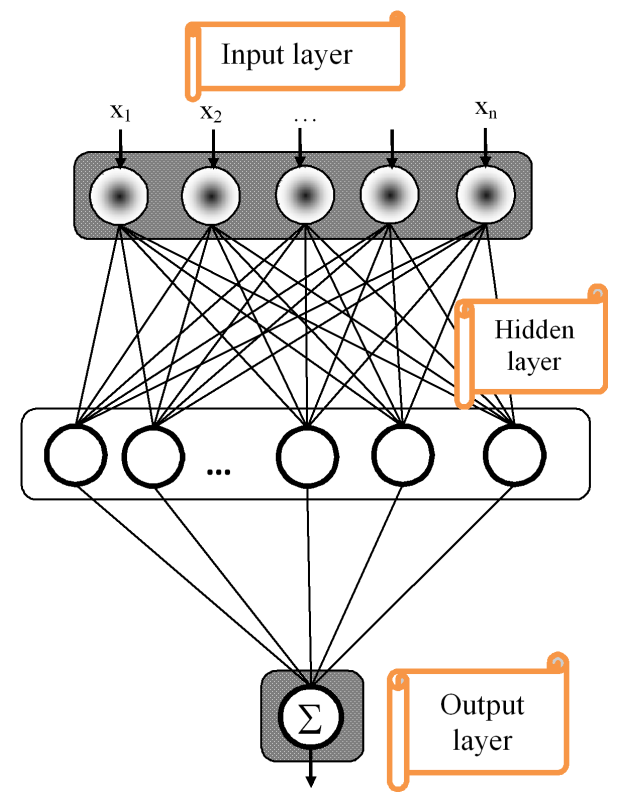

Fig. 2. RBF network with a single output.

In this formulation, $y_{i}$ and $w_{i j}$ are the output and weights, respectively. Later, the transfer (activation) function $\varphi$ is used to recalculate the Euclidean distances, and the outputs are calculated using a weighted linear combination of $\varphi\left(r_{j}\right)$.

$$
\hat{y}=\sum_{j=1}^{n} c_{j}(k) \varphi\left(r_{j}\right) .
$$

In essence, RBF network is a sophisticated linear regression model. The weights are adjusted on a radial basis, and the network is supervised. This type of network provides a fast convergence and can be used for prediction and classification purposes [12].

\section{Results and discussion}

The RBF network is established to estimate the parameters describing the impact resistance of steel fiber reinforced and ordinary concrete. The inputs of the network are selected from basic strength parameters, which can be easily obtained: the compressive strength, splitting tensile strength and ultrasonic pulse velocity. The outputs are number of blows to formation of initial crack and number of blows to failure. Analyses are individually carried out for steel fiber reinforced and ordinary concrete. The scatter plots of the verification data, which constitutes $33 \%$ of overall data, are given in Fig. 3 .
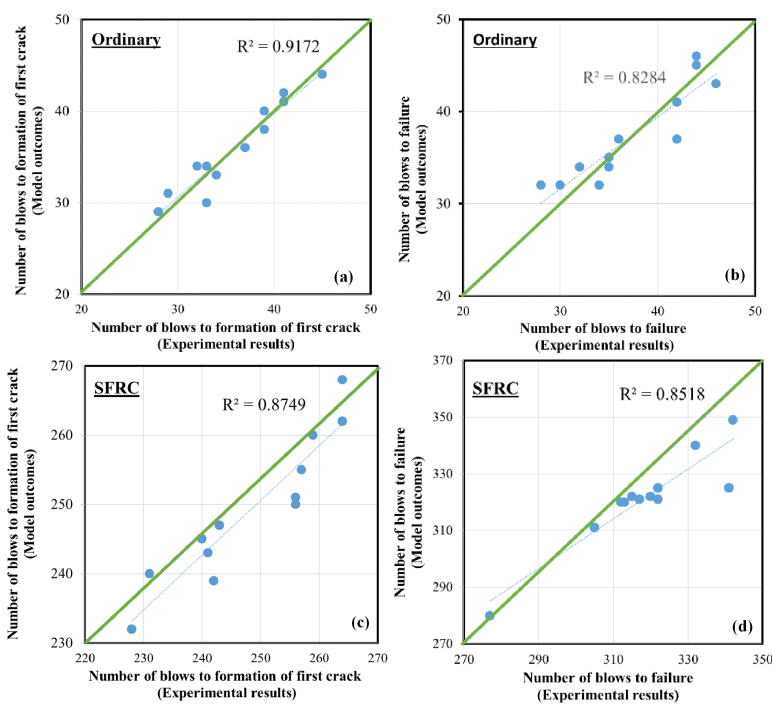

Fig. 3. Scatter plots of experimental results against RBF model outcomes: (a) ordinary concrete, no. of cracks to formation of initial crack, (b) ordinary concrete, no. of blows to failure, (c) steel fiber reinforced concrete, no. of cracks to formation of initial crack, (d) steel fiber reinforced concrete, no. of blows to failure.

TABLE V

RMSE and AAR values for steel fiber reinforced and ordinary concrete mixtures.

\begin{tabular}{c|c|c}
\hline \hline Dataset & RMSE & AAR \\
\hline $\begin{array}{c}\text { Blows to formation of initial } \\
\text { crack - ordinary concrete }\end{array}$ & 1.443 & 1.250 \\
Blows to failure - ordinary concrete & 2.415 & 2.000 \\
Blows to form. of init. crack - SFRC & 4.444 & 3.917 \\
Blows to failure - SFRC & 7.106 & 6.000
\end{tabular}

After the analysis of the scatter plots in Fig. 3, it is clear that RBF networks are capable of establishing input-output relationships to a reasonable degree. For ordinary and reinforced concrete specimens, coefficients of determination $R^{2}$, demonstrating the accuracy of predictions of the number of blows to formation of initial crack, of RBF network, were determined as 0.92 and 0.88 , respectively. These values, obtained for number of cracks 
to failure were 0.83 and 0.85 , for ordinary and steel fiber reinforced concrete, respectively. These values are reasonable, since these parameters in our data set show a great variation and uncertainty (please see Table IV), which makes their prediction a harder task.

Additionally, from the analysis of the scatter plots, it is evident that experimental results are somewhat higher than their predictions, and this ensures more conservative predictions in the number of blows. Moreover, the accuracy of predictions is verified using RMSE (root mean square errors) and AAR (absolute value of average residual) parameters, given in Table $\mathrm{V}$. The root mean square error is a descriptor of the errors in predictions, amplifying large errors:

$$
\text { RMSE }=\sqrt[2]{\frac{1}{n} \sum_{i=1}^{n}\left(y_{i}-\hat{y}_{i}\right)^{2}} .
$$

Additionally, AAR is another important parameter, showing the magnitude of the distances among predictions and experimentally obtained values:

$$
\mathrm{AAR}=\frac{\sum_{i=1}^{n}\left|y_{i}-\hat{y}_{i}\right|}{n} .
$$

Analysis of the RMSE and AAR values, given in Table $\mathrm{V}$, shows that the errors are relatively insignificant, compared with the data in hand. Mathematically speaking, errors among estimations and real values range between 0.1 and $3 \%$. It should be emphasized that, use of larger datasets may provide better approximations.

\section{Conclusions}

In this study, parameters identifying the impact resistance of concrete were modeled by radial basis functions. The following conclusions can be drawn from this study:

1. HKM, FCM, and SOM methods were used to question whether a relationship exists between compressive strength, splitting tensile strength, impact resistance, concrete class and origin of aggregates, used in production of concrete specimens. The results made no sense since these algorithms can make only the distinction between the strength of steel fiber reinforced concrete and ordinary concrete specimens.

2. Radial basis function was successful in estimation of impact resistance of the concrete specimens, using the results of compressive strength, indirect tensile strength and ultrasonic pulse velocity tests.
3. The results have also revealed that $\mathrm{RBF}$ underestimates the number of blows to formation of initial crack and failure and since experienced values are higher, it is evident that outcomes of RBF model are safe to use in practice.

\section{References}

[1] T. Zhan, Z.Wang, J. Ning, Eng. Failure Analysis 56, 233 (2015).

[2] M. Eftekhari, S. Mohammadi, Int. J. Impact Eng. 87, 55 (2016).

[3] H. Kim, G. Kim, J. Namb, J. Kim, S. Han, S. Lee, Compos. Struct. 134, 831 (2015).

[4] S. Aghdamy, D.P. Thambiratnam, M. Dhanasekar, S. Saiedi, Adv. Eng. Software 89, 52 (2015).

[5] H. Jiang, M.G. Chorzepa, Eng. Failure Analysis 55, $63(2015)$.

[6] G.I. Sezer, S. Yazici, A. Sezer, Acta Phys. Pol. A 128, B-37 (2015).

[7] M. Davraz, Ş. Kılınçarslan, H. Ceylan, Acta Phys. Pol. A 128, B-184 (2015).

[8] M. Davraz, Ş. Kılınçarslan, M. Koru, F. Tuzlak, Acta Phys. Pol. A 130, 469 (2016).

[9] J.C. Bezdek, Pattern recognition with fuzzy objective function algorithms, Plenum, New York 1981.

[10] T. Kohonen, Biol. Cybern. 43, 59 (1982).

[11] T. Kohonen, P. Somervuo, Neurocomputing 21, 19 (1998).

[12] S. Haykin, Neural networks, Prentice Hall, New Jersey 1998.

[13] A.B. Goktepe, S. Altun, A. Sezer, Art. Int. Eng. Des. Analysis Man. 29, 55 (2015).

[14] A.B. Goktepe, A. Sezer, G.I. Sezer, K. Ramyar, Constr. Build. Mat. 22, 675 (2008).

[15] D.S. Broomhead, D. Lowe, Complex Systems 2, 321 (1988).

[16] J.A. Leonard, M.A. Kramer, L.H. Ungar, IEEE T. Neural Networks 3, 624 (1992).

[17] L. Fausett, Fundamentals of Neural Networks, Prentice Hall, New Jersey 1994. 